\title{
PREDICTING THE IMPACT ON BUSINESS PERFORMANCE OF ENHANCED INFORMATION SYSTEM USING BUSINESS PROCESS SIMULATION
}

\author{
Yifei Tan \\ Soemon Takakuwa \\ Graduate School of Economics and Business Administration \\ Furo-cho, Nagoya University \\ Chikusa-ku, Nagoya, Aichi 464-8601, JAPAN
}

\begin{abstract}
The estimation of the impact on performance in business process (BP) by introducing an information system (IS) is an important practical problem in investment appraisal. This paper quantitatively investigates the potential of business process simulation (BPS) as an approach for evaluating an expected IS impact on business performance. By introducing the ability to incorporate system variability, scenario analysis, and visual display to communicate process performance, BPS fundamentally enhances process performance analysis and makes it a useful technique providing a realistic evaluation of impact before introducing a particular IS. A real-life case study is discussed, showing how to develop a BPS model in helping analysts and decision makers arrive at more informed choices for systems design and evaluation.
\end{abstract}

\section{INTRODUCTION}

Despite the existence of various approaches and techniques for assisting the design and development of information systems (IS), estimates of the expected benefits of a given IS are still far from easy to obtain, especially for complex, sophisticated IT applications and an intangible, indirect, or strategic impact on business performance (Giaglis et al. 1999). Although the conventional modeling techniques, including flowcharts and spreadsheets, are suitable for answering the "what happens?" question, they are not capable of performing in-depth analysis and in predicting behaviors or the performance of the system under various conditions (Fathee et al. 1998; Profozich 1998; Tumay 1995). Serrano and Hengst (2005) argued that it is not yet clear how to use these conventional modeling techniques to model IS performance measurements.

Several studies have focused on the impact of business process simulation (BPS). For example, Aguilar and Pater (1999) proposed that the main impact of simulation is directed towards performance analysis and design of future processes. Fathee et al. (1998) asserted that simulation adds greater value to the understanding and reengineering of business processes. In some empirical studies, BPS was used to quantify benefits from information systems (Giaglis et al. 1999, 2005, Serrano and Hengst 2005). These studies propose using BPS as the fundamental unit which can provide quantifiable metrics and results when evaluating the impact of a proposed IS within various business process scenario.

In this study, in order to predict the potential business impacts of introducing a new information system, the approach of BPS is also adopted. By presenting a real-life case study, the characteristics of the development of BPS model are outlined.

\section{IMPLEMENTING AN ORDER MANAGEMENT SYSTEM IN A HOUSEHOLD PRODUCTS PRODUCTION COMPANY}

\subsection{Company Background}

Company-Q is a Japanese-based company now located in China. The company operates the manufacture and sale of toothpaste, toothbrushes and about 50 kinds of other household products. The global headquarters and international division of the company are located in Tokyo. In addition to the local headquarters (HQ) and a factory in Qingdao, Company-Q also maintains six sales subsidiaries (distribution center: DC) across China. These are Shenyang DC, Shandong DC, Shanghai DC, Guangzhou DC, Chengdu DC, and Beijing DC. Company-Q intends to expand its operations to several other cities over the next few years. The organization structure of Company-Q is illustrated in Figure 1.

In Company-Q's current operating model, each DC office submits a transportation request to the HQ, according to the month-end stock level and the demand forecast for next month. If the requests are approved, goods are 


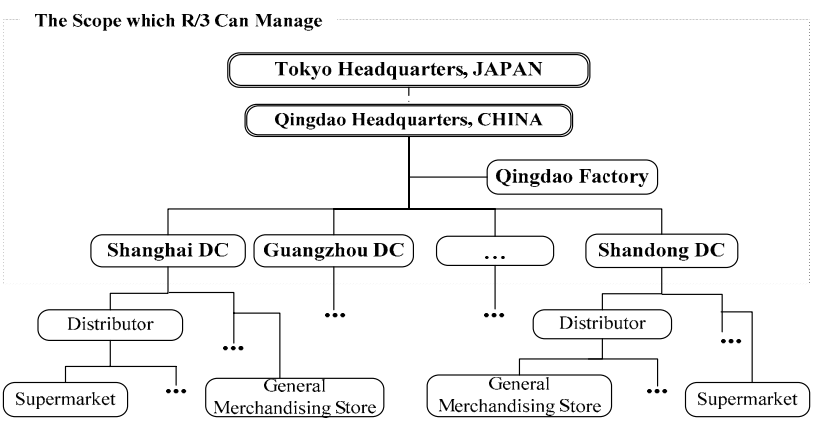

Figure 1: The organization structure of Company-Q

carried to the DC leased warehouses by trucks based on the transportation plan. Afterwards, DC delivers goods to distributors, which are its main customers.

\subsection{Current ERP System and Prospects}

In Company-Q, the SAP $\mathrm{R} / 3^{\circledR}$ system (hereinafter called "R/3"), an ERP (Enterprise Resource Planning) package, was introduced and is used between HQ and DCs. Because there is a restriction on the number of user licenses, the number of users and computers which can access the $\mathrm{R} / 3$ system are quite limited. In this context, it is rare for salespersons who are working in the front line of business to obtain orders or customer data by operating the $R / 3$ system directly.

As shown in Figure 1, the scope of the administration which $\mathrm{R} / 3$ can manage is limited to only that from the HQ to DC. Since distributors are out of the management scope of the $\mathrm{R} / 3$ system in Company-Q, it is difficult to grasp the distributors' inventory accurately, which leads to difficulties in order management, inaccurate demand forecasts, and other problems in production planning.

On the other hand, the management of logistics has been concerned about Company-Q for a long time. In China, the quality of service and the cost of logistics vary enormously by region and the contracted partner. However at present, each DC has its own contracted transport companies and leased warehouses. This situation brings many difficulties in standardizing the logistics at a companywide level.

For the above-mentioned reasons, business strategies are initiated by Company-Q's top management which include the following visions:

- Expanding the range of the inventory management to distributors, so as to raise the quality of, for example, order management and demand forecasting .

- Establishing a regional office system instead of the subsidiary company system now in existence, so as to simplify functions of the DCs, by concentrating the business of logistics, financial and personnel affairs at the HQ. Also to reduce the repeti- tion of organizational functions and the excess of workers.

- Introducing a 3PL (third-party logistics) system, so as to standardize the company's logistics management on a company-wide level.

However, there has been difficulty in attaining the goals above by using only the $\mathrm{R} / 3$ system. In order to accomplish these challenges, Company-Q decided to develop and introduce an original information system named Collaboration Inventory Portal (CIP). The functions of this CIP were blueprinted. A high-level view of CIP's interaction with other information systems is shown in Figure 2.

As shown in Figure 2, CIP connects Company-Q with the R/3 System, the 3PL Provider Company and Distributors, serving as a data interchange station. As an extension and supplement of the functions of the $\mathrm{R} / 3$ system, the CIP system construction is based on the browser/server architecture, so that users can access and operate the system via the internet, without the restriction of requiring installation of clients on user-side computers. Using the CIP system, users can gain useful information such as customer credit limits and unliquidated accounts which are transferred from the R/3 system via EDI (Electronic Data Interchange). These data were hidden in the $\mathrm{R} / 3$ system and were seldom used to review processes until now. These data which are available from the CIP system online will be of great help to the person appraising or examining sales orders in CIP.

Based on the discussion above, it is clear that the CIP system holds an important role in aspects such as the reform of company structure, the introduction of a 3PL system, the improvement of efficiency in order management processes, and the maximum utilization of $\mathrm{R} / 3$.

The following case study is part of a wider research project funded jointly by Company-Q and the Takakuwa laboratory, Nagoya University. The goal of this project is to evaluate the impact and benefits of introducing the CIP system.

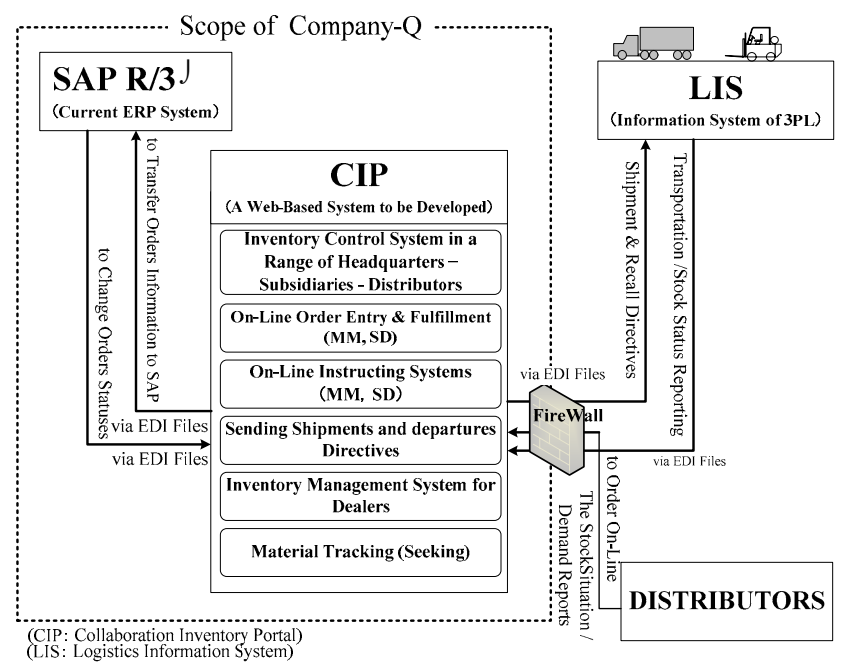

Figure 2: Interaction of CIP with other ISs 


\subsection{Sales and Distribution Process Description}

Before proceeding with examining of the evaluation of business impact and benefits of the CIP system, it is worth detailing the sales and distribution process (hereinafter called "SD process") in this case study. The SD process includes sequent processes, starting with the reception order from customers, to the end process with distribution order delivered to the contracted transport company by company-Q.

From the survey results performed by Company-Q, it is understood that more than $80 \%$ of the influence from CIP is concentrated on the SD process, after CIP is to be introduced. Figure 3 illustrates the existing SD process ("as-is") at a BP level.

In the current SD process, each DC office maintains a sales force that is responsible for contacting customers, reviewing orders and maintaining customer relationships. All of the processes are performed by DC offices. Customers place their orders either with the regional sales manager (RSM) that visits them or directly with a DC (by phone or fax) where orders are reviewed. The reviewed route is different by order type, outside of the R/3 system. If the order is approved, the order data will then be inputted into the $\mathrm{R} / 3$ system where the availability check and customer credit check are performed automatically. The ordered goods are picked up from the DC warehouse and delivered to individual customers, called distributors. There are five types of sales order in Company-Q, named OR (ordinary) order, ZTP (special) order, SO (express) order, FD (return or free) order and BV (cash) order, respectively.

Figure 4 shows the design of the SD process after the CIP is introduced ("to-be"). In the SD process of "to-be", the delivery work is released from the regional office (called DC in "as-is"). The order reviewing process is operated in the CIP system online and varies by the type of sales order. When the inventory in $\mathrm{R} / 3$ changes, the inventory in the CIP system is updated in real time.

First, Distributors enter sales orders into the CIP system online (when a distributor cannot do this, regional sales assistants execute it instead). The CIP system receives it automatically within 24 hours. The CIP system judges the type of order and then delivers them to the corresponding order examination process automatically. If the orders are approved, all the orders from each DC are directed to the HQ where CIP orders are introduced into R/3 via an EDI method as unfinished orders.

After sales orders are finished and saved, the logistics department located at the HQ generates a delivery order (DO) in the R/3 system. After reviewing the delivery order, the logistics department sends the delivery orders data to the 3PL provider company by the EDI method via the CIP system three times a day. Ordered goods are then entered into the delivery process performed by the 3PL company. Every day, the transportation situation and the inventory change list are reported to the CIP system by the 3PL provider company via EDI method. After the CIP system receives a report of delivery confirmation of a delivery order, the shipment settlement process is performed in $\mathrm{R} / 3$ and then goods issues are posted, and the billing process is then triggered.

\subsection{Case Study Objectives and the Scope of Study}

Within this project, the main aim of the work is to provide tangible and quantitative measures of the way business processes and information systems behave, thus predicting the potential impact that the introduction of the CIP system may bring to business processes.

In order to accomplish this objective, the approach of BPS is adopted. The potential impact is measured by comparing the performance on the business process of SD process with and without the CIP system. We need to build a "as-is" model to simulate the current business process, and build a "to-be" model to simulate the future process (after introducing the CIP system). Although it may evaluate the impact of the CIP system from other aspects, for example, the cost measurement or the risk analysis, we have chosen to leave them out of the scope of study in order to keep the target as simple and straightforward as possible.

Moreover, the BPS model is also adapted to a) identify possible limitations and areas of improvement, b) identify non-functional processes, and c) propose alternative business process scenarios.

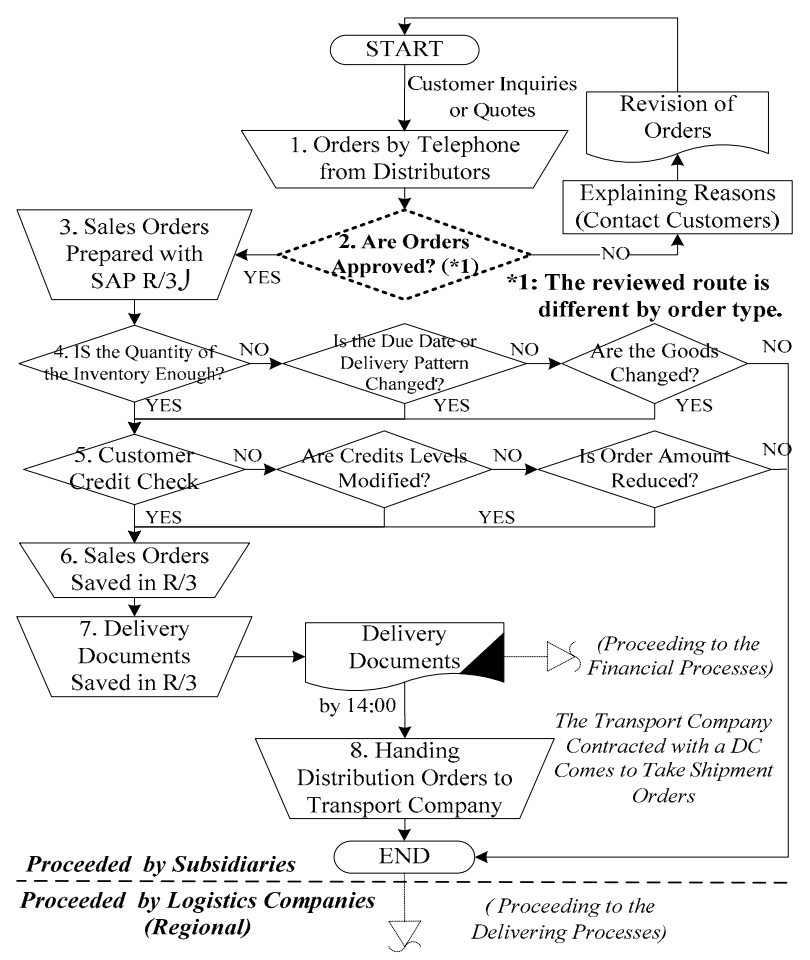

Figure 3: Process map of SD process ("as-is") 


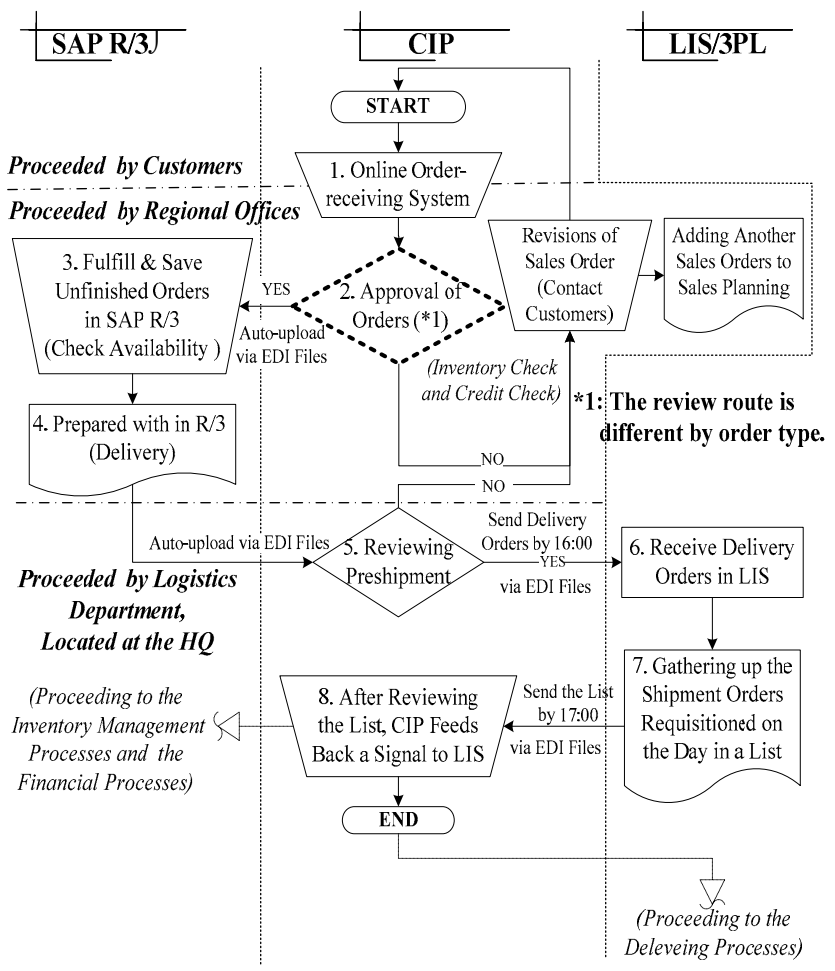

Figure 4: Process map of SD process ("to-be")

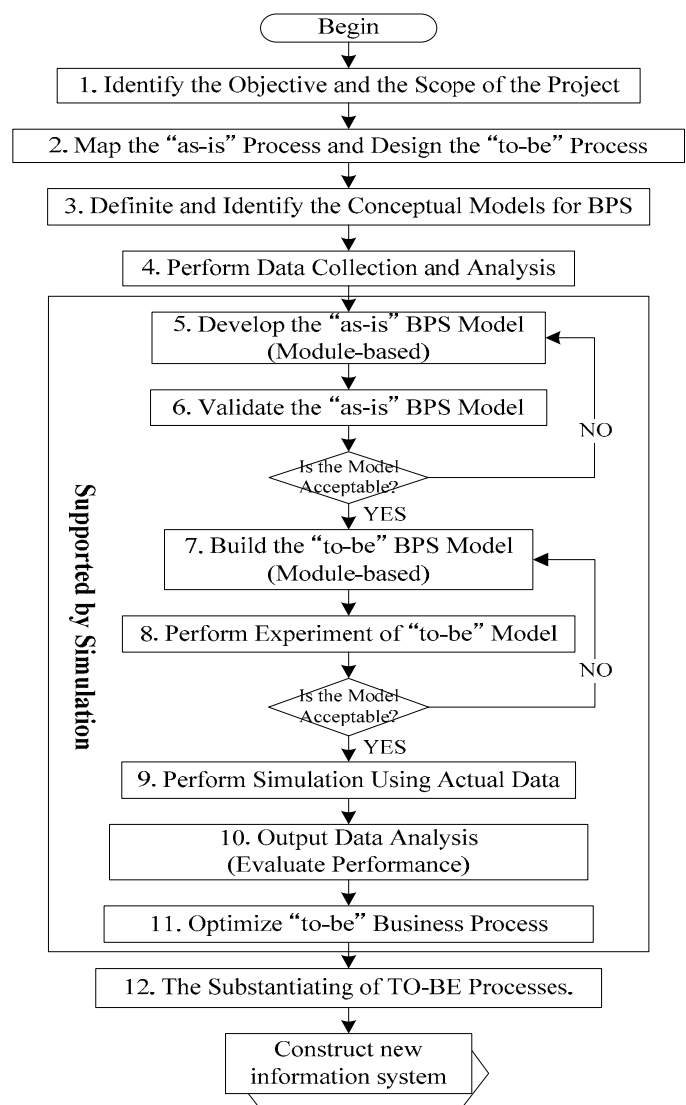

Figure 5: The process of developing BPS models

\section{DEVELOPMENT OF MODULE-BASED BUSINESS PROCESS SIMULATION MODELS}

In this study, the simulation models were developed with Arena ${ }^{\circledR}$, a software package for process analysis and simulation (Kelton et al. 2007).

Figure 5 shows a guideline for developing BPS models. The following subsections are a detailed description of how to develop BPS models to achieve the main objectives. Since Tiers 1-2 were introduced above, we begin our discussion from Tier 3.

\subsection{Defining and Identifying the Conceptual Models for BPS}

After the process maps of "as-is" and "to-be" have been identified, it is necessary to define the conceptual model for the BPS model. The main task at this stage is to detail the definition and activities for each process step. For example, the connection or the relationship between the current and previous processes, the operating location and resources, the data or documents generated, and so forth, which are however not generally depicted in the process map. Figure 6 shows a sample as the conceptual model.

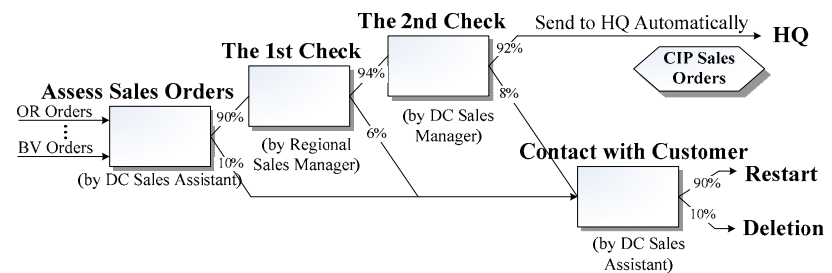

Figure 6: The conceptual model of 2-level-examinationsales-orders in the "to-be" model (Part)

\subsection{Performing Data Collection and Analysis}

The conceptual model constructed earlier needed to be complemented with various exogenous parameters (data) to provide the quantitative basis for the simulation run. The objectives of this study dictate the kind of data to be collected. In this study, such data include, but are not limited to, actual historical sales data, existing lead time, resource levels, and other points. For the "as-is" model, such data can be collected from the database of the R/3 system, or from the workplace by observing and measuring existing activities. For the "to-be" model, some data such as the proceeding time, can be estimated based on the present value or can be acquired through sampling experiments.

Since much of this raw data cannot be inputted into BPS models directly, some input analysis such as probability distribution analysis were performed.

Table 1 shows the parameters provided through the input analysis. 


\subsection{Developing the "as-is" BPS Model}

The most important and difficult part of the entire project proved to be the development of the "as-is" model. As mentioned earlier, Company-Q consists of six DCs, and each DC has five types of orders for the SD process. For orders of the same type, the proceeding processes in each DC are similar. In this situation, inputting parameters to the BPS model is very tedious work.

According to Miwa and Takakuwa (2005), a modulebased system drastically reduces time and effort for modeling and increases efficiency of constructing models. The change reflects only the setting of a series of designated parameters. For this reason, in this study, the modeling approach incorporated the module-based system, by using the template-building features of Arena.

Referring to the conceptual model designed earlier for the "as-is" model, five modules were developed for the five types of orders. Corresponding to the order type, the modules were named as OR Orders, ZTP Orders, SO Orders, FD Orders and BV Orders, respectively. Since different types of orders have different order approval processes (the No.2 Process shown in Figure 3), the program logic of these five modules is different from each other. As a sample, the interface of the OR Orders module is shown in Figure 7.

After the modules were constructed, the "as-is" BPS model was incorporated by selecting and allocating the required modules of the template in Arena as referred to in the process map shown in Figure 3, together with the parameters shown in Table 1.

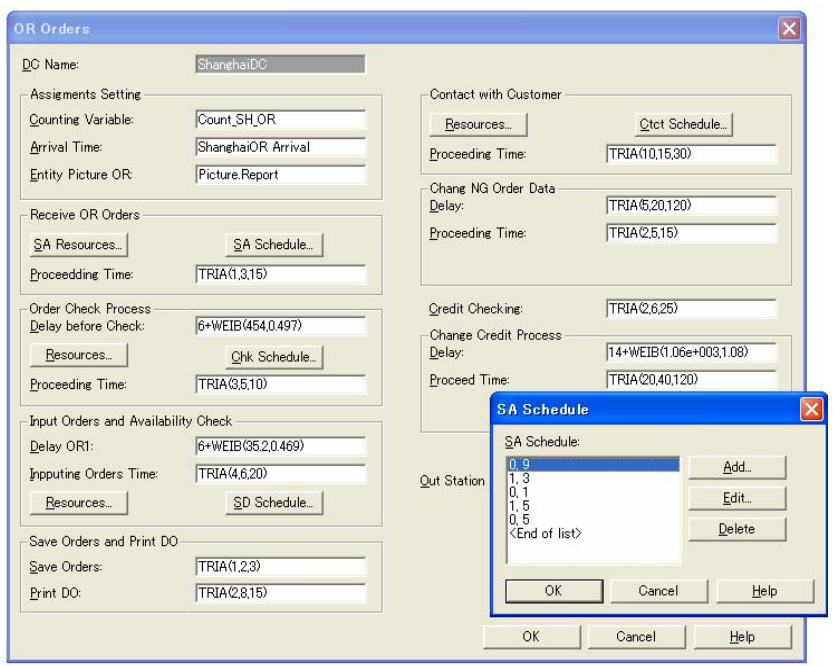

Figure 7: The OR order modules in "as-is" model

\subsection{Validating the "as-is" BPS Model}

This tier aims to ensure that the "as-is" model is an accurate representation of the real system. In order to validate the "as-is" model, the value of a key performance indicator
(KPI) from the running result of the "as-is" model is compared against those from the real world system. Amendment to the "as-is" model should be done until the results of KPI from the "as-is" model match the results from the real world in the best possible way.

If amendments to the "as-is" model" are needed, the "as-is" model should be modified from Tier 5 or even from Tier 4. Furthermore, because many parameters of the "tobe" model are estimated by basing them on those of the "as-is" model, if the parameters in the "as-is" model are changed, then the corresponding parameters in the "to-be" model should also be changed as well.

From the validation and test results, the "as-is" model was accepted as an adequate representation of the realworld system modeled.

\subsection{Building the "to-be" BPS Model}

In many simulation studies, the "to-be" model is developed by modifying the "as-is" models, for example, changing some parameters on the basis of the "as-is" model. However, in our study, as shown in figures 3 and 4, the changes of business process between "as-is" and "to-be" models are too intense to construct the "to-be" model in this way. In this situation, we decided to develop the "to-be" model afresh.

The approach to developing the "to-be" model is similar to the "as-is" model, the module-based approach. In the "to-be" model, two modules were constructed, named "2Level-Examination-Order" and "3-Level-ExaminationOrder", respectively. In the business process of "to-be", orders for types of OR, SO, FD and BV are standardized to 2-Level-Examination-Order, and only ZTP orders are classified into 3-Level-Examination-Order. The parameters inputted to the "to-be" model are summarized in Table 1 and Table 2. As a sample, the interface of the 3-LevelExamination-Order modules is shown in Figure 8.

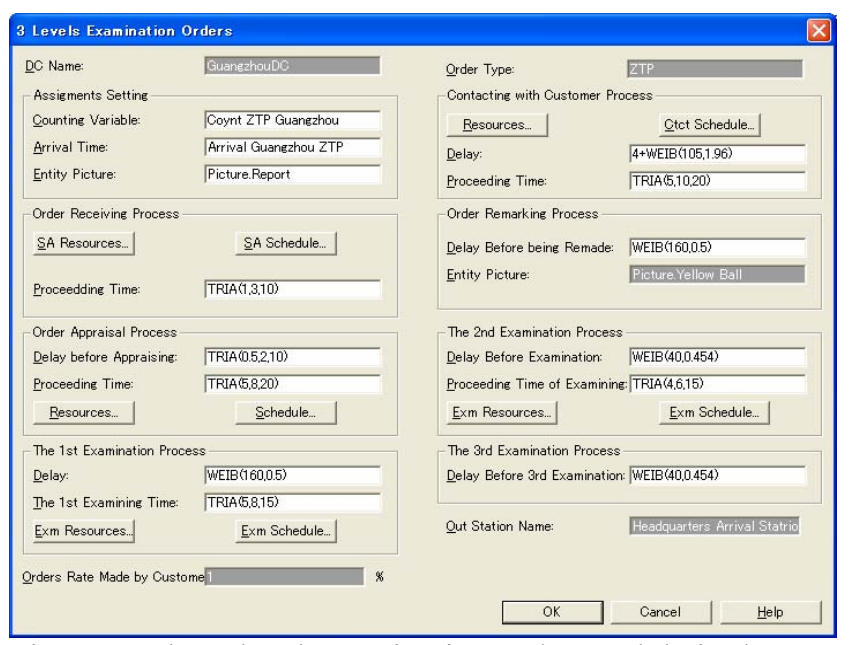

Figure 8: The 3-level-examination-order module in the "tobe" model 


\section{Tan and Takakuwa}

A screen image on running the "to-be" model is shown in Figure 9.

\subsection{Validating the "to-be" BPS Model}

Before the "to-be" BPS model could be used for decision making, like the "as-is" model, it is necessary to validate the reliability of the "to-be" BPS model.

In order to validate the "to-be" model, we took the same approach as in the case of the "as-is" model, compar- ing performance measurements from running results of the "to-be" model against those from sampling experiments or estimations.

Although the CIP system was not yet introduced in actuality, in order to estimate the waiting and processing duration under the business process scenario of "to-be", we did some parts of the sampling experiments, supposing that the CIP system had been introduced. Later, validation was done against these data.

Table 1: List of parameters input to modules

\begin{tabular}{|c|c|c|c|c|c|c|c|c|c|c|c|}
\hline \multirow{3}{*}{ Processes } & \multirow{3}{*}{ Parameter Names } & \multicolumn{5}{|c|}{ "as-is" } & \multicolumn{5}{|c|}{ "to-be" } \\
\hline & & \multicolumn{2}{|l|}{ OR } & \multirow{2}{*}{ (Omitted) } & \multicolumn{2}{|l|}{ ZTP } & \multicolumn{2}{|l|}{ OR } & \multirow{2}{*}{ (Omitted) } & \multicolumn{2}{|l|}{ ZTP } \\
\hline & & Time & CLK & & Time & CLK & Value & CLK & & Time & CLK \\
\hline \multirow{2}{*}{$\begin{array}{l}\text { Receive Orders } \\
\text { from Customer }\end{array}$} & & & & \multirow{10}{*}{ (Omitted) } & & & $100 \%$ & & \multirow{10}{*}{ (Omitted) } & $100 \%$ & \\
\hline & Receive Orders & TRIA( $(1,3,15)$ & $\mathrm{SA}$ & & TRIA( $(1,3,15)$ & $\mathrm{SA}$ & $\operatorname{TRIA}(1,3,10)$ & $\mathrm{SA}$ & & TRIA(1,3,10) & SA \\
\hline \multirow{2}{*}{$\begin{array}{l}\text { Assess Sales } \\
\text { Orders }\end{array}$} & Delay before Check & 6+WEIB $(454,0.497)$ & & & $\begin{array}{l}\text { 14+WEIB }(1.16 \mathrm{e}+ \\
003,1.08)\end{array}$ & & $\operatorname{TRIA}(0.5,2,10)$ & & & $\operatorname{TRIA}(0.5,2,10)$ & \\
\hline & Approval of Orders & $\operatorname{TRIA}(3,5,10)$ & $\mathrm{DCM}$ & & $\operatorname{TRIA}(3,5,10)$ & DCM & $\operatorname{TRIA}(1.5,3,7)$ & $\mathrm{SA}$ & & TRIA( $(1.5,3,7)$ & SA \\
\hline \multirow{2}{*}{$\begin{array}{l}\text { The 1st Check } \\
\text { (Review) }\end{array}$} & Delay & & & & & & $\begin{array}{l}\text { 2+WEIB }(67.5 \\
0.756)\end{array}$ & & & WEIB $(100,0.8)$ & \\
\hline & Review Orders & & & & & & $\operatorname{TRIA}(1,2,5)$ & RSM & & $\operatorname{TRIA}(1,2,5)$ & RSM \\
\hline \multirow{2}{*}{$\begin{array}{l}\text { The 2nd Check } \\
\text { (Review) }\end{array}$} & Delay & & & & & & WEIB $(7.46,0.533)$ & & & WEIB $(40,0.454)$ & \\
\hline & Review Orders & & & & & & TRIA $(1,2,6)$ & $\mathrm{DCM}$ & & TRIA $(1,2,6)$ & DCM \\
\hline \multirow{2}{*}{$\begin{array}{l}\text { The 3rd Check } \\
\text { (Review) }\end{array}$} & Delay & & & & & & & & & WEIB $(40,0.454)$ & \\
\hline & Review Orders & & & & & & & & & $\operatorname{TRIA}(2,3,6)$ & SDr \\
\hline \multirow{2}{*}{$\begin{array}{l}\text { Input Orders and } \\
\text { Availability } \\
\text { Check in } R / 3{ }^{\circledR} \\
\end{array}$} & Delay before being Input & 6+WEIB $(35.2,0.469)$ & & \multirow{12}{*}{ (Omitted) } & $6+\mathrm{WEIB}(35.2,0.469)$ & & & & \multirow{12}{*}{ (Omitted) } & & \\
\hline & Inputting Order & $\operatorname{TRIA}(4,6,20)$ & $\mathrm{SA}$ & & $\operatorname{TRIA}(4,6,20)$ & SA & & & & & \\
\hline $\begin{array}{l}\text { Check the } \\
\text { Credit }\end{array}$ & Customer Credit Check & $\operatorname{TRIA}(2,6,25)$ & SA & & $\operatorname{TRIA}(2,6,20)$ & SA & & & & & \\
\hline \multirow{2}{*}{$\begin{array}{l}\text { Change Cus- } \\
\text { tomers Credits }\end{array}$} & Delay & $\begin{array}{l}\text { 14+WEIB }(1.06 \mathrm{e}+ \\
003,1.08)\end{array}$ & & & $\begin{array}{l}\text { 14+WEIB }(1.16 \mathrm{e}+ \\
003,1.08)\end{array}$ & & & & & & \\
\hline & Adjust Credits Levels & TRIA(20,40,120 & $\mathrm{SA}$ & & $\operatorname{TRIA}(10,20,40)$ & SA & & & & & \\
\hline \multirow{2}{*}{$\begin{array}{l}\text { Contact with } \\
\text { Customers }\end{array}$} & Delay & & & & $\operatorname{WEIB}(160,0.5)$ & & $\operatorname{WEIB}(30,1.96)$ & & & 4+WEIB $(45,1.96)$ & \\
\hline & Proceeding Time & TRIA(10,15,30) & SA & & TRIA(10,20,30) & SA & TRIA $(5,10,18)$ & SA & & TRIA $(5,10,18)$ & SA \\
\hline \multirow{2}{*}{$\begin{array}{l}\text { Change NG } \\
\text { Orders in } R / 3\end{array}$} & Delay & TRIA $(5,20,120)$ & & & TRIA(5,20,120) & & WEIB $(61.8,0.478)$ & & & WEIB $(110,0.8)$ & \\
\hline & Change Order Data & $\operatorname{TRIA}(2,5,15)$ & $\mathrm{SA}$ & & $\operatorname{TRIA}(2,5,15)$ & SA & $\operatorname{TRIA}(2,5,15)$ & $\mathrm{SA}$ & & TRIA $(2,5,15)$ & SA \\
\hline \multirow{3}{*}{$\begin{array}{l}\text { Process Deliv- } \\
\text { ery }\end{array}$} & Delay & & & & & & & & & & \\
\hline & Save Sales Orders & $\operatorname{TRIA}(1,2,3)$ & $\mathrm{SA}$ & & $\operatorname{TRIA}(1,2,3)$ & $\mathrm{SA}$ & & & & & \\
\hline & Print Delivery Orders & TRIA $(2,8,15)$ & $\mathrm{SA}$ & & TRIA $(2,8,15)$ & $\mathrm{SA}$ & & & & & \\
\hline \multirow{3}{*}{ Quote Price } & Print Price & & & & & & & & & & \\
\hline & Delay & & & & & & & & & & \\
\hline & Price Approval & & & & & & & & & & \\
\hline \multirow{2}{*}{$\begin{array}{l}\text { Process Pay- } \\
\text { ment }\end{array}$} & Delay before Payment & & & & $10+$ WEIB(96.4,0.746 & & & & & & \\
\hline & Receive Money & & & & $\operatorname{TRIA}(2,5,15)$ & $\mathrm{SA}$ & & & & & \\
\hline & $\begin{array}{l}\text { Make Returns Applica- } \\
\text { tions }\end{array}$ & & & (Omitted) & & & & & (Omitted) & & \\
\hline $\begin{array}{l}\text { Exchanges and } \\
\text { Returns }\end{array}$ & Delay before Examine & & & & & & & & & & \\
\hline & $\begin{array}{l}\text { Examine Returns Appli- } \\
\text { cations }\end{array}$ & & & & & & & & & & \\
\hline $\begin{array}{c}\text { Send Sales Orders } \\
\text { to the HQ }\end{array}$ & $\begin{array}{l}\text { Delay before being Pro- } \\
\text { ceeding to HQ }\end{array}$ & & & & & & WEIB $(28.8,0.388)$ & & & WEIB $(46.7,0.414)$ & \\
\hline
\end{tabular}

Note: $\mathrm{CLK}=$ Clerk, each clerk has his/her own work schedule. TRIA = Triangular, WEIB = Weibull. SA = DC Sales Assistant, LA = Logistics Assistant, RSM = Regional Sales Manager, DCM = DC Sales Manager, SDr $=$ Sales Director, GM $=$ General Manager. 
Table 2: Processes and parameters in the HQ on SD process

\begin{tabular}{|c|c|c|c|c|c|c|}
\hline $\begin{array}{l}\text { Consummate } \\
\text { Orders in } R / 3 \AA\end{array}$ & $\begin{array}{c}\text { Delay until Examina- } \\
\text { tion by Logistics } \\
\text { Department }\end{array}$ & $\begin{array}{c}\text { Review Delivery } \\
\text { Order by Logistics } \\
\text { Manager }\end{array}$ & $\begin{array}{c}\text { Delay before Sent } \\
\text { to } 3 \mathrm{PL}\end{array}$ & $\begin{array}{l}\text { Sent Deliv- } \\
\text { ery Orders to } \\
\text { 3PL }\end{array}$ & $\begin{array}{l}\text { Send Back to } \\
\text { Check }\end{array}$ & $\begin{array}{c}\text { Contact with } \\
\text { 3PL }\end{array}$ \\
\hline $\operatorname{TRIA}(1,3,8)$ & $\begin{array}{c}3.13 \mathrm{e}+003 * \operatorname{BETA}(0.141, \\
2.77)\end{array}$ & $\operatorname{TRIA}(0.5,1,1.5)$ & WEIB(31.3,0.547) & $\begin{array}{l}\text { TRIA }(2,8,15) \\
\text { seconds }\end{array}$ & $\begin{array}{l}\text { TRIA }(2,10,20) \\
\text { seconds }\end{array}$ & $\operatorname{TRIA}(3,8,20)$ \\
\hline
\end{tabular}

(Unit: minutes)

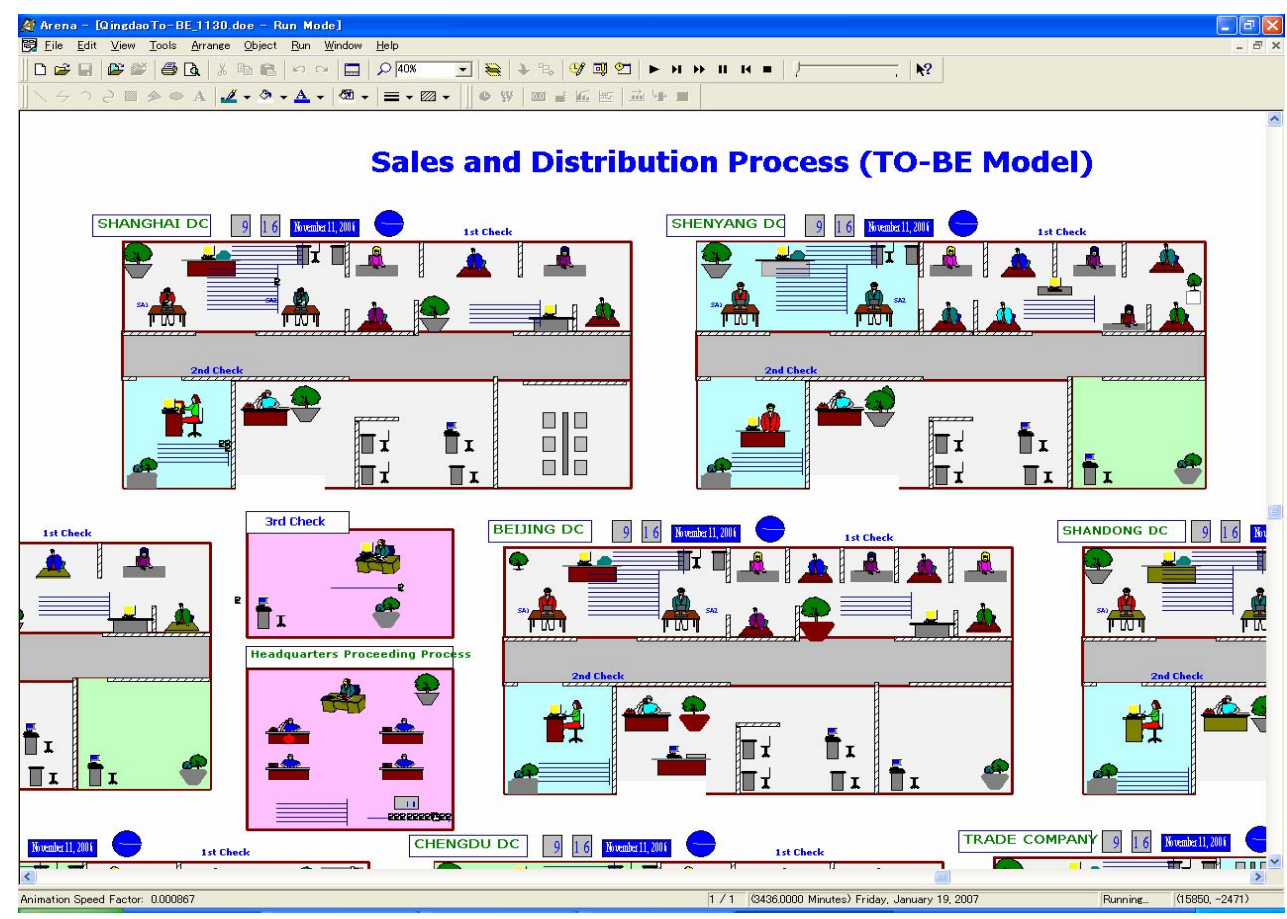

Figure 9: Animation of the "to-be" model

\section{APPLICATION OF BPS: BUSINESS PROCESS PERFORMANCE APPRAISAL}

Once implemented, the BPS model would then be used as a tool to experiment with alternative business process scenarios and obtain quantitative performance data. By measuring the performance of the relevant business operations with and without the information system, one can evaluate the various impacts on business process performance of the proposed information system.

The main business in the SD process that was isolated for modeling were order receiving, order entry, order reviewing and distribution. Therefore, we decided the key performance indicator (KPI) to be monitored was the total lead time (TLT).

$T L T$ is given by:

$$
T L T=\sum_{i=1}^{n} D T_{i}+\sum_{i=1}^{n} W T_{i}+\sum_{i=1}^{n} P T_{i}
$$

where $D T_{i}$ is the delay time of process $i, W T_{i}$ is the waiting time in process $i$, and $P T_{i}$ is the processing time of process $i$. The delay time here refers to the time delay be- fore orders enter the process, and the waiting time refers to the time waiting for the orders to be processed.

In order to provide more decision factors to decision makers, on top of the lead time, we also put the waiting time and the scheduled utilization of resources into our performance indicators. The scheduled utilization of resources in this case, is the rate of the resource (employee) who is busy during his/her working schedule.

In order to compare performance indictors, the "as-is" and the "to-be" BPS model were each used to run a number of replications on different scenarios, using the same arrival source which was the actual data from Company-Q. Table 3 shows the results of the "as-is" model and the "tobe" model for different scenarios. The results suggested that, compared with the "as-is" model, the results of the "to-be" model reported a significant reduction in total lead times, in particular the lead time of an FD order. Also, the time waiting in process, and the scheduled utilization of resources in each scenario are shown in Figure 10 and Figure 11 , respectively.

From the data illustrated in Table 3, Figure 10 and Figure 11, it can be observed that, by introducing the CIP system, the processing time spent in the SD process and 
the utilization of employees are decreased. Thus, employees can process other business in the time saved.

BPS models are not only used to predict the performance of the "to-be" design before resources are committed, but also can be used to support the scenario analysis on business process redesign. Once built, the BPS model allows with little effort the potential to analyze many new designs through its "what-if" capability. For example, in this study, we wanted to test the performance of when the number of DC sales assistants (SA) decrease from a value of 2 people to 1 person. We changed the resource capability of SA in the "as-is" and the "to-be" model respectively. The item "'to-be' $(\mathrm{SA}=1)$ " in Table 3, Figure 10 and Figure 11 show the experiment results.

The BPS model can be used to predict the performance of the system under a number of scenarios determined by the decision maker. In order to investigate the total lead time, 4 scenario experiments were performed. The results are shown in Figure 12. According to Figure 12, these 4 scenarios were conducted in "as-is" and "to-be" models. The number following SA indicates the number of sales assistants. The scenario with the asterisk stands for the best scenario. As shown in Figure 12, both of the scenarios of the "to-be" model obtained the results of the best scenario. However, considering the labor costs, the scenario of "tobe $(\mathrm{SA}=1)$ " is the best one.

Table 3: Total lead times by model (Beijing DC)

\begin{tabular}{|c|c|c|c|c|c|}
\hline $\begin{array}{l}\text { Qrders Type } \\
\text { Models }\end{array}$ & \begin{tabular}{|c} 
BV \\
Orders \\
\end{tabular} & $\begin{array}{c}\text { OR } \\
\text { Orders }\end{array}$ & \begin{tabular}{|l|} 
SO \\
Orders
\end{tabular} & \begin{tabular}{|l|} 
ZTP \\
Orders \\
\end{tabular} & $\begin{array}{l}\text { FD } \\
\text { Orders } \\
\end{array}$ \\
\hline & 2488 & & 38 & 79 & \\
\hline & 1969.11 & 1482.56 & 1826.19 & 2032.25 & \\
\hline & & 493.90 & & & \\
\hline
\end{tabular}

(Time Unit: Minute)

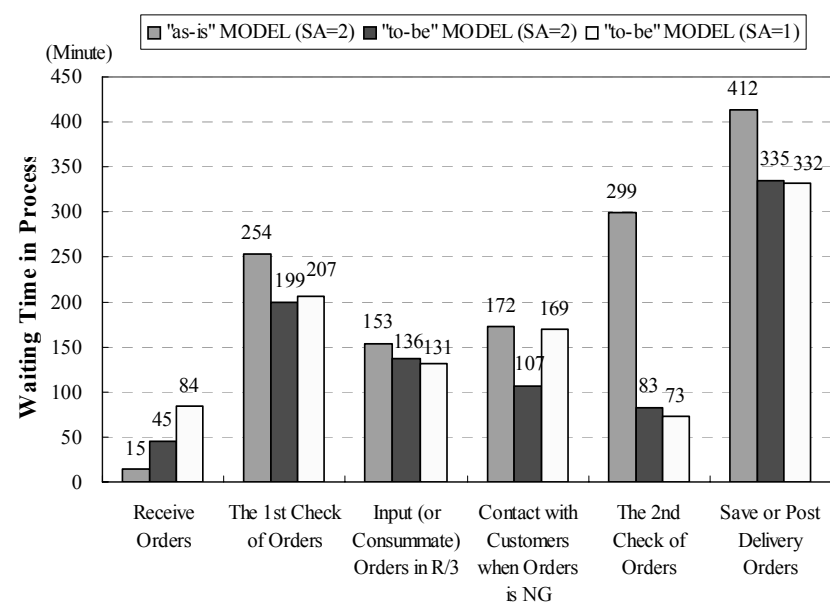

Figure 10: Waiting time in process by scenario

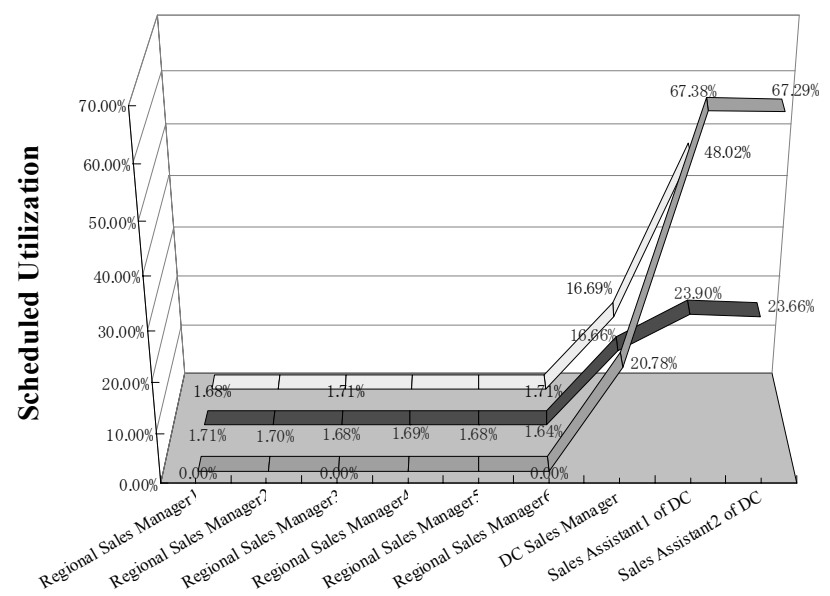

Figures 11: The scheduled utilization of resource by scenario

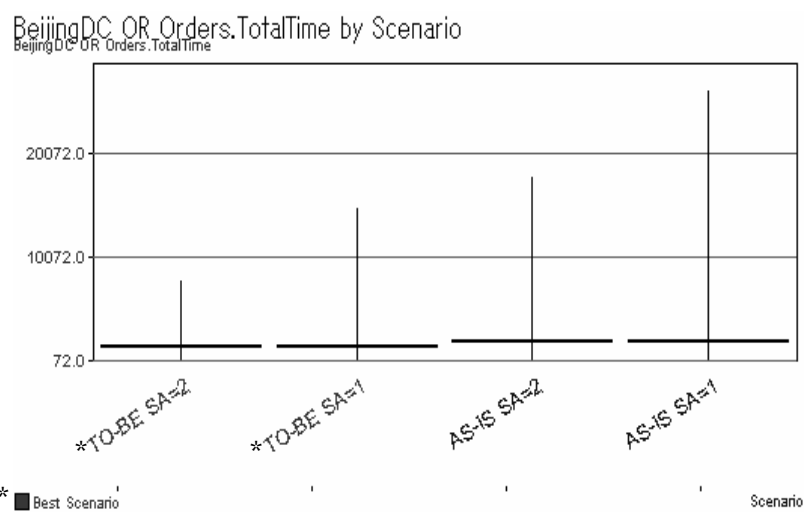

Figure 12: The result of business scenario analysis

In this study, the business impact of the CIP system was appraised by evaluating the performance of business processes. By measuring the performance of the relevant business operations with and without the information system, the necessary quantitative information can be collected to conduct further investment appraisals using financial or other methods.

\section{CONCLUSIONS}

In this paper, the approach of a business process simulation (BPS) was adopted to predict the impact of a proposed web-based order management information system (IS) in a household product production company. In order to accomplish our objectives, the "as-is" and the "to-be" BPS models were implemented respectively. Based on a case study, the characteristics of the BPS approach were outlined.

It was found that BPS model could predict the business impact of a proposed IS quantitatively by evaluating the process performance of a number of measures such as lead time and resource utilization. A BPS provides the op- 
portunity to test for unexpected interaction with the system or check the robustness of the design of business scenarios quantitatively and visually.

\section{ACKNOWLEDGMENTS}

Authors wish to thank Mr. S. Fujishige, Mr. M. Obayashi, Mr. A. Hashimoto, Mr. H.T. Ren, Mr. T. Kawai, Mr. L. Yu, Ms. H. Cui, and Ms. F. Li of Lion Corporation for their assistance in this research.

\section{REFERENCES}

Aguilar, M., and A. Pater 1999. Business process simulation: A fundamental step supporting process centered management. In Proceedings of the 1999 Winter Simulation Conference, ed. P.A. Farrington, H.B. Nembhard, D.T. Sturrock, and G.W. Evans, 1383-1392. Piscataway, New Jersey: Institute of Electrical and Electronics Engineers, Inc.. Available online via <http://www.informs-sim.org/ wsc99papers/202.PDF $>$ [accessed January 31, 2007].

Fathee, M. M., R. Redd, D. Gorgas and B. Modarres. 1998. The effects of complexity on business processes reengineering: Values and limitations of modeling and simulation technologies. In Proceedings of the 1998 Winter Simulation Conference, ed. D.J. Mederios, E.F. Waston, J.S. Carson and M.S. Manivannan, 13391345. Piscataway, New Jersey: Institute of Electrical and Electronics Engineers, Inc..

Giaglis, G. M., V. Hlupic, G. J. de Vreede, and A. Verbraeck. 2005. Synchronous design of business processes and information systems using dynamic processes modeling. Business Process Management Journal 11(5):488-500.

Giaglis, G. M., N. Mylonopoulos, and G. I. Dpukidis. 1999. The ISSUE methodology for quantifying benefits from information systems. Logistics Information Management 14(1/2):50-62.

Kelton, D., R. P. Sadowski, and D. T. Sturrock. 2007. Simulation with ARENA. $4^{\text {th }}$ ed. New York: McGrawHill.

Miwa, K. and S. Takakuwa. 2005. Flexible module-based modeling and analysis for large-scale transportationinventory systems. In Proceedings of the 2005 Winter Simulation Conference, ed. M. E. Kuhl, N. M. Steiger, F. B. Armstrong, and J. A. Joines, 1749-1758. Piscataway, New Jersey: Institute of Electrical and Electronics Engineers, Inc.. Available online via <http://WwW.informs-sim.org/ wsc05papers/216.pdf> [accessed January 31, 2007].

Profozich, D. 1998. Managing Change with Business Process Simulation. New Jersey: Prentice Hall PTR.
Serrano, A. and M. Hengst. 2005. Modelling the integration of BP and IT using business process simulation. Journal of Enterprise Information Management 18(6):740-759.

Tumay, K. 1995. Business process simulation. In Proceedings of the 1995 Winter Simulation Conference, ed. C. Alexopoulos, K. Kang, W. R. Lilegdon, and D. Goldsman, 55-60. Piscataway, New Jersey: Institute of Electrical and Electronics Engineers, Inc.

\section{BIOGRAPHIES}

YIFEI TAN is a Ph.D. candidate in the Graduate School of Economics and Business Administration at Nagoya University in Japan. He received his B.A. Degree from Southwest Jiaotong University, China, in 2001, and M. Sc. Degree in Economics from Nagoya University, Japan, in 2004. His research interests include business process reengineering, supply chain management, and information systems. His current research focuses on the simulation and evaluation of information system impact on business performance. His e-mail address is <d040203dembox. nagoya-u.ac.jp>.

SOEMON TAKAKUWA is a Professor and Chair in the Graduate School of Economics and Business Administration at Nagoya University in Japan. He received his B. Sc. and M. Sc. Degrees in industrial engineering from Nagoya Institute of Technology in 1975 and from Tokyo Institute of Technology in 1977, respectively. His Ph.D. is in industrial engineering from Pennsylvania State University. His research interests include optimization of manufacturing and logistics systems, management information systems and simulation analysis in these systems as well as in hospitals. He has prepared the Japanese editions of both the introduction to simulation using SIMAN and Simulation with ARENA. He has been serving concurrently as a senior staff member of the Department of Hospital Management Strategy and Planning at Nagoya University Hospital. His e-mail address is <takakuwalsoec.nagoya-u.ac. $j \mathrm{p}>$. 